\title{
A Picture is Worth a Thousand Words
}

\section{Practical Use of Videotape in Teaching}

\author{
Linda E. Pinsky, MD, Joyce E. Wipf, MD
}

\begin{abstract}
Videotapes, through vividly displayed clinical images and teaching interactions, are valuable tools for both learners and teachers. Visual images in combination with verbal instruction have been shown to significantly increase recall and retention. Many clinicians and medical teachers are aware of videotape resources, but have not had a chance to develop their use in medical education. In this paper, we discuss creative applications of videotapes in three major categories: presenting information, triggering discussion, and as a tool for direct self-observation and feedback. Videotapes may be valuable for presenting information in settings of didactic instruction; for triggering discussion during teaching workshops; and for self-observation of patient-doctor interactions and learner-teacher encounters. The article presents learnercentered approaches to review a videotaped clinical encounter in order to enhance value and comfort for the learner and teacher. Sources of tapes include on-site videotaping, published educational tapes and commercial tapes shown in accordance with fair use guidelines, examples of which are referenced. Videotapes add another dimension to traditional sources of physician education.
\end{abstract}

KEY WORDS: medical education; videotapes; medical teaching. J GEN INTERN MED 2000;15:805-810.

V ideotape material enhances learning through images that convey the complexity of medical practice. It is a powerful tool to focus a discussion, illustrate clinical cases, and visually demonstrate techniques. In this article, we will explore, through short vignettes, multiple uses of videotapes for medical education and their application. These include demonstration of clinical findings; enhancement of doctor-patient communication; performance-based evaluation; and improvement of teaching and professional skills. We will also discuss how to produce videotapes with particular emphasis on videotaping to examine doctorpatient communication.

Received from the Department of Medicine (LEP, JEW) and Department of Medical Education (LEP), University of Washington, Seattle, Wash.

Address correspondence to Dr. Pinksy: University of Washington Department of Medicine, Campus Box 354760, 4245 Roosevelt Way, NE, Seattle, WA 98105-6920 (e-mail: lpinsky@ u.washington.edu).

\section{THEORETICAL BASIS FOR USE OF VIDEOTAPES}

The impact of visual representation on recall and retention of taught material has been demonstrated. One study of teaching methods found that telling alone, showing material visually alone, and combined telling and showing each resulted in $70 \%$ or greater recall at 3 hours (85\% for combined). However, retention 3 days later was $10 \%$ for telling alone and $20 \%$ for showing alone, compared with $65 \%$ retention for combined telling and showing. ${ }^{1}$

Educational research shows that experiential learning is a cyclical process including concrete personal experiences, reflection, and generalizations, leading to active experimentation with what has been learned. ${ }^{2,3}$ Unfortunately, despite its critical role in learning, reflection is not a skill that is encouraged in medicine nor is time provided for it, particularly during residency. Westberg and Jason wrote, "Many of our traditions in health professions education promote unreflective doing." ${ }^{4}$ Knowles suggests that that trainees learn more efficiently through selfdirected and experiential learning, are aware of their specific learning needs, and want to be able to apply their learning to their immediate circumstances. ${ }^{5}$ Research shows that learning is most effective when it occurs in the context in which the activity will occur. ${ }^{6}$ Thus, viewing videotapes of themselves in actual situations is an ideal opportunity for learners and teachers to reflect on their own behaviors to enhance self-directed learning. ${ }^{7}$ Similarly, viewing videotapes of patients or clinical skills demonstrations is an effective teaching method grounded in these educational premises.

\section{USE OF VIDEOTAPE IN PRESENTATIONS, WORKSHOPS, AND DEMONSTRATIONS}

\footnotetext{
"Pertussis in Adults." The grand rounds topic seemed interesting so I settled back for the usual slides and lecture format. To my surprise, in addition to engaging historical and epidemiological data presented on slides, the presenter played a videotape of an individual with paroxysms of coughing from B. pertussis infection. Now, several months later, as I see my first patient with pertussis, I realize that the presenter's comment, "you will never forget this cough," has proven true.
}

This example depicts how videotapes help to elevate a presentation, workshop, or demonstration. Visual images quickly orient learners to the same concept, add interest, and increase the likelihood that the illuminated point will 
be remembered. ${ }^{8}$ The videotape of pertussis expanded medical knowledge of clinical signs.

Videotapes can trigger or focus an ensuing group discussion to improve learning. ${ }^{9}$ The following videotaped vignette on the role of the ward resident is used to elicit discussion on leadership skills during a resident teaching course ${ }^{10,11}$ :

Resident: This has been the worst call night. It's finally slowing down. Mr. J, the patient with COPD, how has he been doing?

Intern: Well, he was looking worse, so I got a blood gas and his $\mathrm{pH}$ is 3.02, $\mathrm{pCO}_{2} 80, \mathrm{pO}_{2} 48$.

Resident: Wait, $\mathrm{pCO}_{2}$ 80. He needs to be intubated.

Intern: He is intubated.

Resident: And you didn't call me? How did this happen?

Intern: The fellow was there and you seemed really busy. He let me do the intubation.

Resident: You can't do these things yourself! Let's go see him right away.

This episode, based on an actual incident, is followed by short scenes that track the senior resident as she calms down and then returns to discuss the incident with the intern. ${ }^{12}$ In presenting the vignette, the group leader solicits audience responses as to what went well, why conflict occurred, and possible solutions. By projecting themselves into realistic situations, the viewers can anticipate potential problems and develop strategies to solve them.

Teaching with videotapes requires specialized preparation. Discussion participants often will notice an aspect of the encounter that the leader has not noticed or planned to discuss. When using video vignettes as triggers, the leader must be prepared to lead the discussion with both flexibility and direction. Using multiple copies of the videotape preset to the appropriate vignette avoids the delay and audience impatience that may occur as the leader scans for the next scene. Ascertain that the equipment works and have a substitute plan should a previously functioning videocassette recorder suddenly stop working. In that circumstance, avoid the common temptation to tell the audience what they missed. Shorter clips (2 minutes or less) are helpful, because that is generally the limit of the audience's attention span for video. As one experienced teacher commented, "As I use videotape more, I have learned to show less, talk less, and give the audience more time to react." 13

\section{USE OF VIDEOTAPE TO IMPROVE TEACHING SKILLS}

A junior faculty member was a little disappointed in the workshop she attended on "How To Give Dynamic Presentations." The lecture and group discussions were good; participants were videotaped giving a 5-minute talk, and the feedback on hers was complimentary. Still, she left unsure that the experience had made her a better teacher. At home, she watched the videotape made of her talk. "I never realized I did that!" Although it was ini- tially disconcerting to see herself on tape, she found it so beneficial that she periodically taped and reviewed her presentations. She blossomed as a speaker.

Most medical training programs provide attending physicians little instruction, supervision, or feedback for educational approaches. ${ }^{14}$ Videotaping is an effective way to review teaching behavior and styles. ${ }^{15-18}$ Tapes permit self-evaluation, demonstration of improvement in teaching skills over time, and creation of a portfolio of taped teaching events for program evaluation and promotion. After overcoming the initial shock of viewing themselves, teachers often recognize their particular strengths as educators. Self-confidence may increase, enhancing teacher effectiveness. Physicians can use videotaping to view their skills in actual learning situations, such as clinical precepting and small group interactions as well as formal presentations. It is recommended that less than a quarter of the videotape should feature the teacher alone; the majority should focus on the teachers and learner(s) interacting with each other and in group settings and interactions among learners as well. In reviewing videotapes of teaching skills, in addition to factors similar to those involved in doctor-patient interactions, consider teaching elements such as maintaining eye contact, using learners' names, and involving various learners. ${ }^{19}$ The review can be done alone or with a mentor who can frame the discussion in terms of effective learner interactions and away from concern about appearance, voice, etc.

Viewing published videotapes of attending residents who are preceptors can provide helpful teaching examples, reflecting interactions "before" and "after" educational interventions. ${ }^{20,21}$ Attendings noted for their excellent attending skills can be videotaped "in action" in clinical settings to model teaching behavior. ${ }^{22}$ Reaction to a videotape of an "excellent clinician" may vary because as even the most expert teacher will be found by a skilled audience to have areas for improvement, thus providing a good starting point for discussion of various practical teaching skills.

\section{USE OF VIDEOTAPE TO DEMONSTRATE PROFESSIONAL SKILLS}

Many of the skills needed to practice medicine are best taught by example, such as viewing an experienced clinician giving bad news, as in the vignette below.

\footnotetext{
"Mrs. K., we got the results back from pathology. Some of the cells do show changes that are cancerous." The residents sat spellbound as the program director showed them the videotape of himself and a patient. He then discussed how to give bad news to patients with the residents, commenting on what he thought he did well and what he realized he would do differently after seeing himself on videotape.
}

The director, via his use of videotape, demonstrated both techniques for giving bad news as well as the process of reflection that allows him to improve his own communication skills. By framing communication skills in 
terms of a process of reflection and continual improvement rather than "the correct approach," the teacher alleviates some of the learners' fears of being videotaped or performing poorly or being judged and rather focuses their attention on identifying their strengths and correcting weaknesses. After a few months of videotaping his interactions with patients, the director created a wealth of teaching examples and was able to both instruct the residents and improve his own approaches. ${ }^{23}$

\section{USING VIDEOTAPES TO ENHANCE CLINICAL EXAMINATION SKILLS}

\begin{abstract}
Attending: (Turning to patient) Mr. G, is it all right with you if we spend a few minutes looking at your nails? We may talk "medicine" but we will explain what we are saying. (Patient shakes head yes)

(To resident) You mentioned that Mr. G had clubbing? How did you examine for that?
\end{abstract}

Resident: (Laughing, sheepishly) Probably not very well. His nails are curved and I remember something about feeling for sponginess. (demonstrates)

Attending: (Encouragingly) Good. That's one technique. Do you know of any other? (Long pause, resident shakes head no) Let me demonstrate.

Videotapes can help to teach basic and advanced physical diagnosis and procedural skills techniques. Appropriate use of history and physical examination is essential to quality clinical practice, ${ }^{24,25}$ and there is a renewed interest in bedside teaching rounds that include patients. There are many indications that current medical residents are deficient in some aspects of physical diagnosis. ${ }^{26-30}$ In one study, residents made errors in the cardiac examination in $56.7 \%$ of the patients evaluated; half of these errors were considered clinically important. ${ }^{31}$ However, faculty and community practitioners, trained in an era that de-emphasized bedside teaching, might lack physical diagnosis skills and role models. A study of faculty assessment found that attending physicians were often unable to detect both subtle and obvious mistakes made by residents in history and physical examinations. ${ }^{32}$ Interview and physical exam demonstration on videotape can provide efficient instruction in exam maneuvers and improve resident physical diagnosis skills. ${ }^{33}$

\section{USE OF VIDEOTAPE FOR FEEDBACK AND EVALUATION}

Dr. S [2nd year resident] and Dr. V [attending] sit intently watching the screen:

[VIDEO]

Dr. S: Mrs. L, the chest x-ray is doesn't show any pneumonia. I did notice several old rib fractures. Have you ever been told that before?

Mrs. L: Oh yeah, I got them from falling. Had one too many when I was younger. (laughter)

Dr. S: Are you still drinking?
Mrs. L: Not much.

Dr. S: That's good. Do you have any rib pain?

Dr. V [attending]: Let's stop the tape and talk about that. Do you think Mrs. $L$ is still drinking?

Dr. S [resident]: Yes, but I didn't know how to get her to say it...

Filming resident-patient interactions provides an opportunity for both resident self-assessment and faculty assessment of resident-patient communication and feedback. The resident is observed in action, an element of education often noted to be lacking. ${ }^{34}$ The resident's videotape examples can be compiled into a portfolio documenting her/his skills and progress over time. ${ }^{35}$ Specific content can be reinforced. For example, increased self-awareness of deficiencies in preventive health care and improved skills were documented after residents viewed their own patient encounters. ${ }^{36}$

\section{General Tips for Viewing Videotapes with Learners}

Learners are often hesitant initially about being videotaped, although they report finding the experience very rewarding once it has been done. Initial reluctance may be overcome by a collegial approach, using videotapes of faculty first or those of fellow residents along with their testimonials about the value of the process. Additionally, it may be helpful to specifically address concerns about physical appearance and refocus the observation on the interaction between the doctor and patient. Considerations when viewing portions of the videotape are as important as the actual tape. A learner-centered guide to videotape review (Table 1) can be used by the trainee independently or by the teacher in a learner-centered manner (unpublished videotape). This approach enhances selfdirected learning. The learner-centered guide also provides a framework for both trainee and teacher during a potentially complex and challenging session. Learners generally find it helpful to choose a specific aspect to focus on in reviewing an encounter. Experienced users of videotape review suggest that an effective method for review is to allow the resident to view the film first and select which portions will be reviewed with the attending. ${ }^{37}$ An important issue during viewing is who handles the remote control and has the power of starting and stopping the tape! ${ }^{38}$ If logistically possible, concomitant patient review of the video can provide another helpful perspective.

\section{Using Videotapes to Improve Uniformity in Evaluations}

Supervising physicians often have disparate evaluations of resident performance, as shown in one study of faculty who reviewed a videotape of a resident examining a new patient. Thirty-one percent of the faculty graded the resident unsatisfactory or marginal, while $69 \%$ of the 


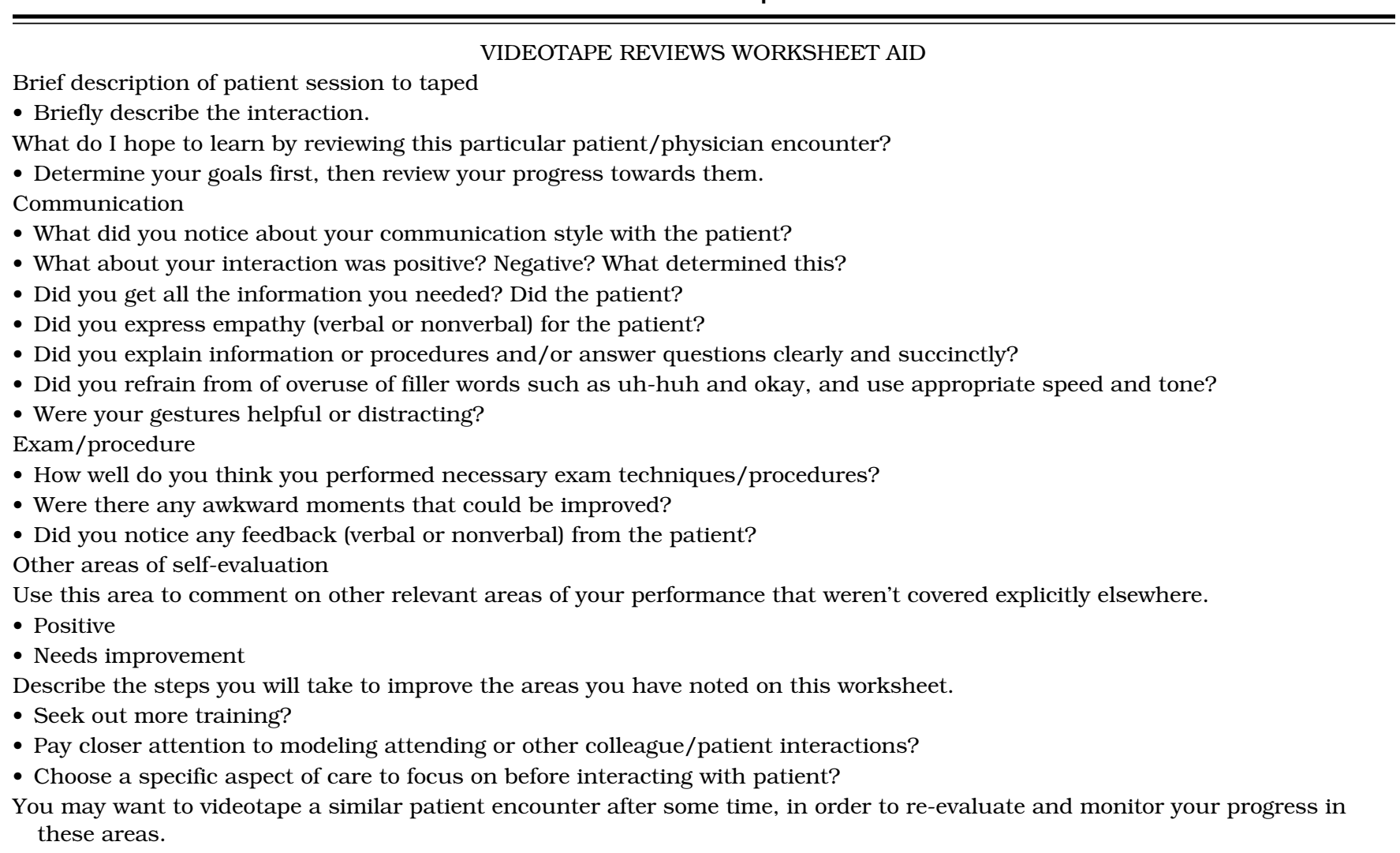

faculty who viewed the same tape rated the resident satisfactory to superior. By viewing and discussing videotapes of residents as a group, faculty can develop standards for attending evaluations of residents. ${ }^{31}$ Practicing physicians may also benefit through self-evaluation by reviewing tapes of their own doctor-patient interactions. Small group discussions with colleagues in a supportive atmosphere, in addition to individual review, enhance the efficacy of videotapes. ${ }^{39}$

\section{RECORDING COMMERCIAL SOURCES FOR EDUCATIONAL USE}

I led a session with the residents about doctor-patient interactions. I had taped a television sitcom episode the night before: one where a character, after discovering her doctor had written in her medical record that she is a "bad patient," gets caught trying to steal her own chart. The residents loved it. And the absurdity of the show gave them the space from their own guilt to examine the concepts about patients they were developing in the process of becoming a doctor.

When using video clips from commercial sources, such as television, one must consider that these works are copyrighted, which controls the performance and display of the work. The exclusive rights of copyright are limited by the doctrine of "fair use" of the materials, by which others may use the materials without restriction. The law specifies four factors to decide whether a particular use of a work is "fair use": (1) the purpose of the use (whether commercial or nonprofit); (2) the nature of the work (e.g., whether news reporting or creative art); (3) the amount copied; and (4) the economic impact of the use on the market value of the work.

The application of these factors to real-life situations allows for considerable interpretation. Consensus guidelines (not law) have been established about the "fair use" concept for recording and presenting television broadcast programs for educational purposes. The guidelines allow recording a program in its entirety for a limit of two teaching episodes, both within the first 10 days after the recording is made. After the 10 days, the teacher may retain the recording an additional 35 days for "teacher evaluation purposes," and then erase the tape. The owners of the copyright may grant written permission for use of commercial material when it is consistent with fair use (University of Washington Attorney General's Office, personal communication, 1996).

\section{PRODUCING YOUR OWN VIDEOTAPES}

\section{Filming Doctor-Patient Interactions}

Videotaping a doctor-patient interaction for provider education can be done with a camcorder in the exam room or through the use of a room with videotaping capacity remotely wired. Trial tapes should be made in advance in the rooms to be used, paying careful attention to sound 
quality and lighting concerns. Prior to filming, the educational rationale for the videotape should be explained to the patient and signed permission obtained. It is often more acceptable to patients if the camera is primarily filming the doctor and if the physical exam is omitted.

\section{Producing Teaching Videotapes}

The first step in the production of a teaching videotape is to define the purpose of the tape. While a single videotape may serve multiple purposes, a clear view of the intended purpose of the videotape will help guide subsequent issues that arise during filming or editing.

Consider whether the audience will be a group or an individual. Will the audience watch the tape in its entirety in a continuous manner or will a facilitator choose specific segments? Assess available resources for the videotape production. Costs may include clerical support to schedule patients, filming and editing crew and/or videotaping equipment, the availability of a studio or permission to film "on-location" in the hospital or clinic, as well as space availability at those sites.

In creating videotape vignettes, some videotapes present a "wrong" followed by a "right" version of each vignette, while other have realistic presentation intermixing strengths and weaknesses. The former approach is particularly helpful in portraying scenes of feedback and evaluation as learners desire examples of successful approaches. The latter intermixed approach is most appropriate for experienced clinicians and teachers and to demonstrate situations where the reality of the scene resonates with the learners, who then appreciate the chance to discuss real life nuances of teaching.

Decide between scripted text versus spontaneous action, or some combination of the two. In determining site, consider the benefits and drawbacks of "realism." Use of a filming studio produces cinemagraphically more sophisticated scenes through the use of multiple cameras providing multiple angles on or views of the scene. Studio production generally has better sound production with less background or extraneous noise as compared to on-site production. It allows tighter control of the filming and therefore often requires fewer retakes, etc. However, onsite shooting offers realistic scenes that may be more credible with your audience and more accurately reflect their experience. Similar considerations are involved in the decision whether to use actors versus actual physicians, patients, and students in the videotape. In contrast to actors, who tend to improve with filming, attending physicians and residents tend to do their best acting on the first or second try and then become more stilted with repeat filming. Doctors, while adding mannerisms and nuances that make the characters more realistic, lack the awareness of features such as sound projection and camera angle that actors possess. In addition, it may be difficult to free up doctors' time for videotaping. For videotapes to use within your own program, taping people known to the viewers can help break the ice or add enter- tainment value; however, be aware of the risk of viewers identifying too closely with those featured.

The quality of videotape is improved by having professional equipment and professionals filming the action, but obviously these involve greater expenses than camcorder productions. The cost of a professional crew can be offset in part by doing one's own pre-editing. In order to do this, make very detailed decisions about where to cut in and cut out. By working with a professional editor who is sympathetic to your cost restraints, you can become aware of a few basic editing techniques such as fade in and out, cutaways, overlays, etc., which will visually enhance the tape and allow you to edit out undesired portions.

\section{SUMMARY}

In this article, we have considered many uses of videotapes in medical education, in teaching and in providing feedback to trainees. In a supportive environment, teachers and learners benefit from self-reflection about their own behaviors noted on videotape. Evaluation of the usefulness of visual aids has shown enhanced recall of subject material, especially when combined with verbal instruction. Videotape materials specifically have been evaluated through self-perceived benefits after teaching improvement courses and as an effective tool in determining attending physician criteria for resident evaluation and level of consistency between evaluators.

Future study of videotapes in medical education should include outcome measures. Videotape effectiveness could be assessed by an outcome such as teaching evaluations before and after a teaching skills intervention that includes videotape reviews of lecturing skills and teaching on rounds. To evaluate the impact of videotapes on the clinical encounter, one could compare history-taking and physical examination skills before and after videotape feedback. Although videotapes of resident-patient encounters have been shown to enhance residents' recognition of their own preventive health practice behaviors, patient health outcomes could also be assessed.

Because Web-based tools are increasingly being used to teach and transmit material for self-directed learning, videotapes on a Web site may enhance information by visual demonstrations. We are currently evaluating a physical diagnosis Web site containing videotape demonstrations and its impact on medical student comprehension of physical examination techniques. ${ }^{40}$ Further study should include outcomes such as test performance and clinical skills.

\section{REFERENCES}

1. Dwyer FM. Strategies for Improving Visual Learning. State College, Pa: Learning Services; 1978;1-20.

2. Kolb DA. Experiential Learning. Englewood Cliffs, NJ: Prentice Hall; 1984.

3. Smith CS, Irby DM. The roles of experience and reflection in ambulatory care education. Acad Med. 1997;72:32-5. 
4. Westberg J, Jason H. Fostering learners' reflection and self-assessment. Fam Med. 1994;26:278-82.

5. Knowles MS. The Modern Practice Of Adult Education: From Pedagogy To Andragogy. 2nd ed. New York: Cambridge Books; 1980.

6. Godden DR, Baddeley AD. Context dependent memory in two natural environments: on land and under water. Br J Psychol. 1975; 66:325-31.

7. Kagan NI, Kegan H. Interpersonal process recall. In: Dowrick PW, ed. Practical Guide to Using Video in the Behavioral Sciences. New York: John Wiley and Sons; 1991:221-30.

8. Tversky A, Kahneman D. The framing of decisions and the psychology of choice. Science. 1981;211:453-8.

9. Biggs SJ. Trigger tapes and training. In: Dowrick PW, ed. Practical Guide to Using Video in the Behavioral Sciences. New York: John Wiley and Sons; 1991:203-20.

10. Wipf JE, Pinsky LE, Burke W. Turning interns into residents: a practical course preparing residents for their teaching and leadership roles. Acad Med. 1995;70:591-6.

11. Wipf JE, Orlander JD, Anderson JJ. The effect of a teaching skills course on interns' and students' evaluations of their residentteachers. Acad Med. 1999;74:938-42.

12. Wipf JE, Pinsky LE. The Role of the Senior Resident: Team Manager, Leader and Teacher (videotape and manual). Seattle, Wash: University of Washington Press; 1994.

13. Pinsky LE, Irby DM. If at first you don't succeed: using failure to improve teaching. Acad Med. 1997;72:973-6.

14. Irby, DM. Faculty development and academic vitality. Acad Med. 1993;68:760-3.

15. Gaff JG. Toward Faculty Renewal. San Francisco, Calif: JosseyBass; 1975.

16. Skeff KM. Evaluation of a method for improving the teaching performance of attending physicians. Am J Med. 1983;75:465-70.

17. Skeff KM, Stratos G, Campbell M, Cooke M, Jones HW. Evaluation of the seminar method to improve clinical teaching. J Gen Intern Med. 1986;1:315-22.

18. Friedman M, Stomper C. The effectiveness of a faculty development program: a process-product experimental study. Rev High Educ. 1983;7:49-65.

19. Krupnick CG. The uses of videotape replay. In: Barnes LB, Christensen CR, Hansen AJ, eds. Teaching and the Case Method. Boston, Mass: Harvard Business School Press; 1994:296-303.

20. Kroenke K. Attending Rounds: Obstacles and Opportunities (videotape). Bethesda, Md: Walter Reed Army Medical Center; 1994.

21. Skeff KM. Stanford Faculty Development Program Instructional Videotapes. Palo Alto, Calif: Stanford University School of Medicine.

22. Wipf JE, Pinsky LE. Teaching in the Ambulatory Setting: From Conference Room to Bedside (videotape and manual). Seattle, Wash: University of Washington Press; 1994.
23. Pinsky LE, Monson D, Irby D. How excellent teachers are made: reflecting on success to improve teaching. Adv Health Sci Educ. 1998;3:207-15.

24. Fletcher RH, Fletcher SW. Has medicine outgrown physical diagnosis? Ann Intern Med. 1992;117:786-7.

25. Peterson MC, Holbrook JH, Von Hales D, Smith NL, Staker LV. Contributions of the history, physical examination, and laboratory investigation in making medical diagnoses. West J Med. 1992; 156:163-5.

26. Oddone EZ, Waugh RA, Samsa G, Corey R, Feussner JR. Teaching cardiovascular examination skills: results from a randomized controlled trial. Am J Med. 1993;95:389-96.

27. St. Clair EW, Oddone EZ, Waugh RA, Corey GR, Feussner JR. Assessing house staff diagnostic skills using a cardiology patient simulator. Ann Intern Med. 1992;117:751-6.

28. Wray NP, Friedland JA. Detection and correction of house staff error in physical diagnosis. JAMA. 1983;249:1035-7.

29. Mangione S, Nieman LZ, Gracely E, Kaye D. The teaching and practice of cardiac auscultation during internal medicine and cardiology training. A nationwide survey. Ann Intern Med. 1993;119: 47-54.

30. Craige E. Should auscultation be rehabilitated? N Engl J Med. 1988;318:1572-8.

31. Johnson JE, Carpenter JL. Medical house staff performance in physical examination. Arch Intern Med. 1986;146:937-41.

32. Noel GL, Herbers JE Jr, Caplow MP, Cooper GS, Pangaro LN, Harvey $\mathrm{J}$. How well do internal medicine faculty members evaluate the clinical skills of residents. Ann Intern Med. 1992;117:757-65.

33. Pinsky LE, Wipf JE. Physical Diagnosis Series: I. Return to the Bedside with a Master Clinician (Videotape). Seattle, Wash: University of Washington Health Sciences Center for Educational Resources; 1999.

34. Ende J. Feedback in clinical medical education. JAMA. 1983; 250:777-81.

35. Beckman HB, Frankel RM. The use of videotape in internal medicine training. J Gen Intern Med. 1994;9:517-21.

36. Hays RB. Teaching health promotion and illness prevention to trainee general practitioners. Med Teach. 1991;13:223-6.

37. Premi J. An assessment of 15 years' experience in using videotape review in a family practice residency. Acad Med. 1991;66:56-7.

38. Steinert Y. Twelve tips for using videotape reviews for feedback on clinical performance. Med Teach. 1993;15:131-9.

39. Lundevall S, Njolstad I, Aaraas I. Stop the video and involve the observers: an inter-reflective method to stimulate doctors' learning about their own consultations with patients. Med Teach. 1994;16:189-95.

40. Pinsky LE, Wipf JE. Advanced Physical Dx. Accessed at: http:// depts.washington.edu/physdx. 